\title{
An Approach for Generating Weights Using the Pairwise Comparison Matrix
}

\author{
Zaher Sepehrian $\mathbb{D}^{1},{ }^{1}$ Sahar Khoshfetrat $\mathbb{D}^{1},{ }^{1}$ and Said Ebadi ${ }^{2}{ }^{2}$ \\ ${ }^{1}$ Department of Mathematics, Tabriz Branch, Islamic Azad University, Tabriz, Iran \\ ${ }^{2}$ Department of Mathematics, Ardabil Branch, Islamic Azad University, Ardabil, Iran \\ Correspondence should be addressed to Sahar Khoshfetrat; saharkhoshfetrat@iaut.ac.ir
}

Received 18 August 2021; Revised 9 October 2021; Accepted 19 October 2021; Published 24 November 2021

Academic Editor: Ching-Feng Wen

Copyright (C) 2021 Zaher Sepehrian et al. This is an open access article distributed under the Creative Commons Attribution License, which permits unrestricted use, distribution, and reproduction in any medium, provided the original work is properly cited.

\begin{abstract}
Data envelopment analysis (DEA) has been used for obtaining weights for the analytic hierarchy process (AHP), an approach known as DEAHP. This method sometimes identifies more than one decision criterion or alternative as DEAHP-efficient. To overcome this problem, this paper proposes a new approach that not only generates appropriate weights for the decision criteria or alternatives, but also differentiates between DEAHP-efficient decision criteria or alternatives. To this end, we propose a DEA model with an assurance region and a cross-weight model that prioritizes decision criteria or alternatives by considering their most unfavorable weights. Two numerical examples are also provided to illustrate the advantages and potential applications of the proposed model.
\end{abstract}

\section{Introduction}

An important issue in the analytic hierarchy process (AHP) is obtaining a priority vector from a pairwise comparison matrix, which has widely been investigated in AHP articles [1-3]. Therefore, the key issue is how to determine the weights of decision criteria or alternatives [4-6]. Since the advent of this technique, it has been theoretically developed multiple times and applied for various purposes (e.g., review studies of Kheybari et al. [7] and Emrouznejad and Marra [8]).

Several methods have been proposed in AHP-related articles for the determination of local weights based on the pairwise comparison matrices [9-18]. Each of these methods has specific advantages and disadvantages, and thus, none of them can be considered the best. Although the eigenvector method (EM) has been strongly recommended and preferred by Saaty [19], there is no general agreement on its superiority (e.g., Mikhailov [20] and Srdjevic [21]).

The data envelopment analysis (DEA) method, proposed by Charnes, Cooper [22], has been used for prioritization in AHP. In this approach, decision criteria or alternatives in a pairwise comparison matrix are considered decision-making units (DMUs). Moreover, the elements on the rows of the pairwise comparison matrix are the outputs of DMUs, and the efficiency of DMUs is considered priorities of the pairwise comparison matrix. Accordingly, Ramanathan [23] proposed a DEAHP method to obtain both weights and cumulative weights in AHP. Although DEAHP can generate true weights for consistent pairwise comparison matrices, it generates illogical and meaningless weights when it comes to inconsistent pairwise comparison matrices. Wang, Chin [24] and Wang, Chin [25] detailed the disadvantages of DEAHP by providing numerical examples. To overcome these issues, they proposed a DEA model with an assurance region (AR) to generate weights in the AHP. The DEA/AR model can generate intuitive and even logical weights for both consistent and inconsistent pairwise comparison matrices. Wang, Parkan [26] proposed a linear programming method to generate the most desirable weights from pairwise comparison matrices. Wang and Chin [27] proposed a DEA model for prioritization in AHP. Instead of the efficiency of each DMU, the proposed model defines relative efficiency as its priority. As a result, it generates the most desirable 
weights, which are close to the weights of the eigenvector of the pairwise comparison matrices.

The most desirable weights for each decision criterion or alternative are assessed from its view, which is called selfevaluation $[28,29]$. When a decision criterion or alternative evaluates its best weight, it also evaluates other decision criteria or alternatives. Such weights, evaluated using other criteria or alternatives, are called cross-weights [30]. The evaluations done by other criteria or alternatives are called peer-evaluation. Obviously, cross-weights may not be desirable for decision criteria or alternatives. Therefore, the use of the most desirable weights is not suitable for a comprehensive decision-making.

To generate a comprehensive weight that is also logical for every decision criterion or alternative, Wang, Luo [28] proposed the cross-weight evaluation technique for weight differentiation. The cross-weight evaluation assessed the weights of a pairwise comparison matrix not only from its standpoint, but also from a peer standpoint. Therefore, the weights generated from the cross-weight evaluation technique are more logical and fair. The models proposed by Wang et al. [28] were among the optimistic models in DEA. Although those models are more optimal than available DEAHP models in differentiation, similar to other DEAHP models, they may sometimes evaluate some decision criteria or alternatives at the same level, making decision-making problematic.

The present paper proposed a new approach, called "analysis of the most undesirable weight," to obtain the weights of decision criteria and alternatives. It enables us to rank a set of decision criteria and alternatives, even those assessed at the same level from an optimistic view. The principal condition for the analysis of the most undesirable weight is that, in addition to the most desirable weight, the most undesirable weight can also be assigned to every decision criterion and alternative. The most desirable and undesirable weights for a decision criterion or alternative define the weight interval of that criterion or alternative. Two numerical examples will be provided to show the advantages and potential applications of the proposed model.

The remaining parts of the paper are organized as follows: Section 2 briefly reviews the DEAHP models for the generation of the most desirable weights for pairwise comparison matrices. Section 3 deals with the cross-weight evaluation technique from a pessimistic standpoint. Section 4 presents numerical examples. Section 5 presents comparison with other prioritization methods. Section 6 is devoted to the conclusion.

\section{DEAHP Models for Generating Most Desirable Weights}

Assume that

$$
A=\left(a_{i j}\right)_{n \times n}=\left[\begin{array}{cccc}
a_{11} & a_{12} & \cdots & a_{1 n} \\
a_{21} & a_{22} & \cdots & a_{2 n} \\
\vdots & \vdots & \cdots & \vdots \\
a_{n 1} & a_{n 2} & \cdots & a_{n n}
\end{array}\right],
$$

is a pairwise comparison matrix with $a_{i i}=1$ and $a_{j i}=1 / a_{i j}$ for $j \neq i$ and $W=\left(w_{1}, \ldots, w_{n}\right)^{T}$ is its priority vector. In DEAHP, each row of $A$ is considered a DMU, and each column is considered an output. Accordingly, Wang, Chin [25] proposed DEA model (2) to generate weights from pairwise comparison matrices $A$ :

$$
\begin{array}{ll}
\max & w_{o}, \\
\text { s.t. } & \left\{\begin{array}{l}
w_{i}=\sum_{j=1}^{n} a_{i j} v_{j} \leq 1, \quad i=1, \ldots, n, \\
\frac{w_{j}}{\beta} \leq v_{j} \leq \frac{w_{j}}{n}, \quad j=1, \ldots, n,
\end{array}\right.
\end{array}
$$

where $o$ refers to the criterion or alternative under the evaluation. By solving model (2) for each $w_{o}(o=1, \ldots, n)$, the most desirable weights for $n$ decision criteria or alternatives can be obtained. $v_{j}(j=1, \ldots, n)$ are decision variables, and $w_{j} / \beta \leq v_{j} \leq w_{j} / n \quad(j=1, \ldots, n)$ are the $\mathrm{AR}$ imposed on the DEA model. $\beta$ is the upper boundary of the maximum eigenvector of the pairwise comparison matrix $A=\left(a_{i j}\right)_{n \times n}$, which is determined from the following equation:

$$
\beta=\min \left\{\max _{i}\left(\frac{1}{r_{i}} \sum_{j=1}^{n} a_{i j} r_{j}\right), \max _{i}\left(\frac{1}{c_{i}} \sum_{j=1}^{n} a_{j i} c_{j}\right)\right\},
$$

where $r_{1}, \ldots, r_{n}$ and $c_{1}, \ldots, c_{n}$ are, respectively, the sums of rows and columns of $A=\left(a_{i j}\right)_{n \times n}$. If there is a set of positive weights $v_{j}^{*},(j=1, \ldots, n)$ to fulfill $w_{o}^{*}=1$, the decision criterion or alternative is called DEAHP efficient; otherwise, it is called DEAHP nonefficient. Typically, the best decision criterion or alternative can be selected from DEAHP-efficient decision criteria or alternatives.

Another technique for generating weight in the DEAHP is the use of cross-weight evaluation to obtain priorities. Model (2) only considers the most desirable weights obtained from self-evaluation and may generate several optimal weight vectors. To solve the problem of nonuniqueness, Wang et al. [28] proposed the cross-weight model (4) that generates unique weights: 


$$
\begin{aligned}
& \max \sum_{j=1, j \neq o}^{n} w_{j} \text {, } \\
& \text { s.t. }\left\{\begin{array}{l}
\sum_{j=1}^{n} a_{o j} v_{j}=w_{o}^{*}, \\
w_{i}=\sum_{j=1}^{n} a_{i j} v_{j} \leq 1, \quad i=1, \ldots, n, \\
\frac{w_{j}}{\beta} \leq v_{j} \leq \frac{w_{j}}{n}, \quad j=1, \ldots, n,
\end{array}\right.
\end{aligned}
$$

where $w_{o}^{*}$ is the most desirable weight of criterion or alternative under investigation based on model (2).

\section{DEAHP Models for Generating Most Undesirable Weights}

Model (2) may recognize more than one decision criterion or alternative as efficient. These efficient decision criteria or alternatives cannot be differentiated based on their most desirable weights. However, we can consider the most undesirable weights. The most undesirable weight is in contrast to the most desirable weight and represents the weight of each decision criterion or alternative in the most undesirable condition. Theoretically, the most desirable and undesirable weights should be obtained in the same range, which should present an interval for each decision criterion or alternative. For example, they can be measured in the interval of $[\alpha, 1]$, where $\alpha>0$ is a predefined parameter [31-33]. The corresponding model can be created as follows:

$$
\begin{aligned}
& \min \widehat{w}_{o}, \\
& \text { s.t. }\left\{\begin{array}{l}
\widehat{w}_{i}=\sum_{j=1}^{n} a_{i j} v_{j} \geq \alpha, \quad i=1, \ldots, n, \\
\frac{\widehat{w}_{j}}{\beta} \leq v_{j} \leq \frac{\widehat{w}_{j}}{n}, \quad j=1, \ldots, n .,
\end{array}\right.
\end{aligned}
$$

Nevertheless, if the most undesirable weight is measured in this way, the major problem is the need to predefine an appropriate value for $\alpha$. To avoid the problem of determining the value of $\alpha$, the most undesirable weight of each decision criterion or alternative can be measured with the following model:

$$
\begin{aligned}
& \min \widehat{w}_{o} \\
& \text { s.t. }\left\{\begin{array}{l}
\widehat{w}_{i}=\sum_{j=1}^{n} a_{i j} v_{j} \geq 1, \quad i=1, \ldots, n \\
\widehat{w}_{j} / \beta \leq v_{j} \leq \widehat{w}_{j} / n, \quad j=1, \ldots, n .
\end{array}\right.
\end{aligned}
$$

This model can be solved for all considered decision criteria and alternatives. The decision criterion or alternative with the greatest weight can be selected. The advantage of model (6) relative to model (2) is that it allows for differentiating between decision criteria and alternatives of DEAHP efficient. If there was a set of positive weights for which the value of an optimal objective function of model (6) is 1 or $\widehat{w}_{o}^{*}=1$, it would be said that the decision criterion or alternative is DEAHP inefficient; otherwise, it is called DEAHP non-inefficient.

Theorem 1. If $A=\left(a_{i j}\right)_{n \times n}$ was a perfectly consistent pairwise comparison matrix, then model (6) would generate the following weights:

$$
\widehat{w}_{i}^{*}=\frac{\widehat{w}_{i}}{\min _{j \in\{1, \ldots, n\}}\left\{\widehat{w}_{j}\right\}}, \quad i=1, \ldots, n,
$$

which are the normalization of true weights $\widehat{w}_{i},(i=1, \ldots, n)$ of the pairwise comparison matrix $A=\left(a_{i j}\right)_{n \times n}$.

Proof. Since $A=\left(a_{i j}\right)_{n \times n}$ is a perfectly consistent pairwise comparison matrix, it can be recognized by the weights of eigenvector $\widehat{w}_{j}=1 / \sum_{i=1}^{n} a_{i j}(j=1, \ldots, n)$ in the form of $a_{i j}=\widehat{w}_{i} / \widehat{w}_{j} \quad(i, j=1, \ldots, n)$. Accordingly, $\quad \sum_{j=1}^{n}\left(v_{j} / \widehat{w}_{j}\right)$ $\geq 1 / \widehat{w}_{i}, \quad(i=1, \ldots, n) \quad$ can be obtained from $\sum_{j=1}^{n} a_{i j} v_{j}=\sum_{j=1}^{n}\left(\widehat{w}_{i} / \widehat{w}_{j}\right) v_{j}=\widehat{w}_{i} \sum_{j=1}^{n}\left(v_{j} / \widehat{w}_{j}\right) \geq 1, \quad(i=1$, $\ldots, n)$. Therefore, we have $\sum_{j=1}^{n}\left(v_{j} / \widehat{w}_{j}\right)$ $\geq \max _{i}\left(1 / \widehat{w}_{i}\right)=1 / \min _{j \in\{1, \ldots, n\}}\left\{\widehat{w}_{j}\right\}$. The minimum value of the objective function of model (6) can be obtained in the form of $\widehat{w}_{o}^{*}=\widehat{w}_{o} \sum_{j=1}^{n}\left(v_{j}^{*} / \widehat{w}_{j}\right)=\widehat{w}_{o} / \min _{j \in\{1, \ldots, n\}}\left\{\widehat{w}_{j}\right\}$, where $\widehat{w}_{o} \in\left\{\widehat{w}_{1}\right.$, $\left.\ldots, \widehat{w}_{n}\right\}$.

Model (6) only considers the most undesirable weights obtained from self-evaluation and may generate several optimal weight vectors. To solve the problem of nonuniqueness, cross-weight model (8), which generates unique weights, is recommended:

$$
\begin{array}{ll}
\min & \sum_{j=1, j \neq o}^{n} \widehat{w}_{j}, \\
\text { s.t. } & \left\{\begin{array}{l}
\sum_{j=1}^{n} a_{o j} v_{j}=\widehat{w}_{o}^{*}, \\
\widehat{w}_{i}=\sum_{j=1}^{n} a_{i j} v_{j} \geq 1, \quad i=1, \ldots, n, \\
\widehat{w}_{j} / \beta \leq v_{j} \leq \widehat{w}_{j} / n, \quad j=1, \ldots, n,
\end{array}\right.
\end{array}
$$

where $\widehat{w}_{o}^{*}$ is the most undesirable weight of criterion or alternative under investigation, based on model (6).

\section{Numerical Examples}

In this part, two numerical examples were investigated using the proposed approach to show its application and capability in the differentiation of efficient decision criteria or alternatives. 
Example 1. Consider the following pairwise comparison matrix of Wang and Chin [27]:

$$
A=\left[\begin{array}{ccccc}
1 & 1 / 3 & 1 / 3 & 1 & 1 / 2 \\
3 & 1 & 1 / 2 & 1 / 2 & 1 \\
3 & 2 & 1 & 1 / 2 & 2 \\
1 & 2 & 2 & 1 & 1 \\
2 & 1 & 1 / 2 & 1 & 1
\end{array}\right] .
$$

This pairwise comparison matrix has a good consistency $\mathrm{CR}=0.0999$. $\beta=6.3810$ was obtained for this pairwise comparison matrix. Table 1 shows the priorities obtained from EM and DEA/AR models (2) and (6). According to Table 1, it can be seen that EM and the DEA/AR model (6) evaluate $C_{3}$ as the most important criterion or alternative. DEA/AR models (2) and (6) differ in the evaluation of $C_{3}$ and $C_{4}$. The DEA/AR model (2) assesses $C_{3}$ and $C_{4}$ at the same level (defines $C_{3}$ and $C_{4}$ as efficient) and cannot differentiate between them, while the DEA/AR model (6) can easily differentiate $C_{3}$ from $C_{4}$, and evaluates $C_{3}$ as more important than $C_{4}$. In other words, DEA/AR model (6) provides a general rank of decision criteria or alternatives.

Tables 2 and 3 show the results from the evaluation of cross-weights obtained from DEA/AR models (2), (4), (6), and (8). Obviously, the mean cross-weights generated using the DEA/AR models (2) and (4) (Table 2) indicate that $C_{3}$ and $C_{4}$ are at the same level of importance, whereas the mean cross-weights generated using the DEA/AR models (6) and (8) (Table 3) indicate that $C_{3}$ is more important than $C_{4}$. Therefore, the mean cross-weights obtained from DEA/AR models (6) and (8) have greater differentiation performance than the mean cross-weights obtained from DEA/AR models (2) and (3).

Example 2. Consider the supplier selection problem of BEKO (a major TV manufacturer in Turkey), derived from Sevkli et al. [34]. The hierarchical structure of the supplier selection problem for purchasing CRTs is presented in Figure 1. It consists of six evaluation criteria, 25 subcriteria, and three suppliers. The six evaluation criteria are as follows:

$$
\begin{aligned}
& C_{1} \text { : performance assessment } \\
& C_{2} \text { : human resources } \\
& C_{3} \text { : quality system assessment } \\
& C_{4} \text { : manufacturing } \\
& C_{5} \text { : business criteria } \\
& C_{6} \text { : using information technology }
\end{aligned}
$$

Each criterion is divided into 3-6 subcriteria, forming a total of 25 subcriteria. These 25 subcriteria are as follows:

$$
\begin{aligned}
& C_{11}: \text { shipment Quality } \\
& C_{12} \text { : delivery } \\
& C_{13} \text { : cost analysis } \\
& C_{21} \text { : number of Employees } \\
& C_{22} \text { : organizational structure } \\
& C_{23} \text { : training }
\end{aligned}
$$

$$
\begin{aligned}
& C_{24}: \text { number of technical staff } \\
& C_{31}: \text { management commitment } \\
& C_{32}: \text { inspection } \\
& C_{33}: \text { quality planning } \\
& C_{34}: \text { quality assurance } \\
& C_{41}: \text { production capacity } \\
& C_{42}: \text { predictive and preventive maintenance } \\
& C_{43}: \text { lead-time } \\
& C_{44}: \text { up-to-date techniques and equipment } \\
& C_{45}: \text { transportation-storage and packaging } \\
& C_{46}: \text { new product development } \\
& C_{51}: \text { reputation } \\
& C_{52}: \text { geographic location } \\
& C_{53}: \text { price } \\
& C_{54}: \text { patent } \\
& C_{55}: \text { technical capacity } \\
& C_{61}: \text { radio-frequency identification (RFID) } \\
& C_{62}: \text { electronic data interchange (EDI) } \\
& C_{63}: \text { internet }
\end{aligned}
$$

For anonymity, the three supplier companies are named by numbers 1,2 , and 3 . In Tables $4-16$, the pairwise comparison matrix has been provided for six evaluation criteria, 25 subcriteria, and three suppliers. Moreover, their local weights are reported in the last two columns of Tables 4-16, using the EM and model (8).

The local weights of three suppliers given each subcriterion of each criterion are presented in Tables 17-22 to obtain a compound weight vector of each criterion. In Table 23 , the compound weight vectors are accumulated in the form of a comprehensive weight vector relative to the supplier accumulation. In Tables 17-23, the weights of EM and model (8) are both normalized until their maximum value equates to 1 . According to Table 23, EM and model (8) generate similar final decisions. They assessed Supplier 2 as the best supplier.

\section{Comparison with Other Prioritization Methods}

This section compares the proposed prioritization method with Eigenvector Method (EM), Least Squares Method (LSM) [35], Weighted Least Square Method (WLSM) [10], Logarithmic Least Squares Method (LLSM) [11], and Correlation Coefficient Maximization Approach (CCMA) [36] to indicate their differences, advantages, and disadvantages.

According to Saaty [2], EM calculates eigenvector weights by solving the following eigenvector equations:

$$
\sum_{j=1}^{n} a_{i j} w_{j}=\lambda_{\max } w_{i}, \quad i=1, \ldots, n,
$$

where $\lambda_{\max }$ is the maximum eigenvalue of pairwise comparison matrix $A, w_{i}(i=1, \ldots, n)$ applies in $w_{i}>0$, and we have $\sum_{i=1}^{n} w_{i}=1$. A weakness of EM is its non-linearity. 
TABle 1: Priority of pairwise comparison matrix $A$ and their ranks.

\begin{tabular}{|c|c|c|c|c|c|}
\hline \multirow{2}{*}{ Model } & \multicolumn{5}{|c|}{ Decision criteria or alternatives } \\
\hline & $\mathrm{C}_{1}$ & $\mathrm{C}_{2}$ & $\mathrm{C}_{3}$ & $\mathrm{C}_{4}$ & $\mathrm{C}_{5}$ \\
\hline EM & $0.1129(5)$ & $0.1763(4)$ & $0.2661(1)$ & $0.2648(2)$ & $0.1799(3)$ \\
\hline DEA/AR model (2) & $0.4454(5)$ & $0.6836(4)$ & $1.0000(1)$ & $1.0000(1)$ & $0.6945(3)$ \\
\hline DEA/AR model (6) & $1.0000(5)$ & $1.4716(4)$ & $2.2291(1)$ & $2.1827(2)$ & $1.5448(3)$ \\
\hline
\end{tabular}

TABLE 2: Results from the cross-weight evaluation based on DEA/AR models (2) and (4).

\begin{tabular}{lcccccr}
\hline \multirow{2}{*}{ Criteria or alternatives } & \multicolumn{3}{c}{ Target criterion or alternative } & \multicolumn{2}{c}{ Average cross-weights } \\
& $\mathrm{C}_{1}$ & $\mathrm{C}_{2}$ & $\mathrm{C}_{3}$ & $\mathrm{C}_{4}$ & $\mathrm{C}_{5}$ & Rank \\
\hline $\mathrm{C}_{1}$ & 0.4454 & 0.4454 & 0.4454 & 0.4454 & 0.4454 & 0.4454 \\
$\mathrm{C}_{2}$ & 0.6836 & 0.6836 & 0.6836 & 0.6836 & 0.6836 & 0.6836 \\
$\mathrm{C}_{3}$ & 1 & 1 & 1 & 1 & 1 & 1 \\
$\mathrm{C}_{4}$ & 1 & 1 & 1 & 1 & 1 & 1 \\
$\mathrm{C}_{5}$ & 0.6945 & 0.6945 & 0.6945 & 0.6945 & 0.6945 & 1 \\
\hline
\end{tabular}

TABle 3: Results from the cross-weight evaluation based on DEA/AR models (6) and (8).

\begin{tabular}{lcccccc}
\hline \multirow{2}{*}{ Criteria or alternatives } & \multicolumn{4}{c}{ Target criterion or alternative } & \multicolumn{2}{c}{ Average cross-weights } \\
& $\mathrm{C}_{1}$ & $\mathrm{C}_{2}$ & $\mathrm{C}_{3}$ & $\mathrm{C}_{4}$ & $\mathrm{C}_{5}$ & 1 \\
\hline $\mathrm{C}_{1}$ & 1 & 1 & 1 & 1 & 1 & 5 \\
$\mathrm{C}_{2}$ & 1.4774 & 1.4716 & 1.5240 & 1.5683 & 1.4716 & 1.5026 \\
$\mathrm{C}_{3}$ & 2.2421 & 2.2431 & 2.2291 & 2.3184 & 2.2431 & 2.2552 \\
$\mathrm{C}_{4}$ & 2.2878 & 2.2993 & 2.2628 & 2.1827 & 2.2993 & 2.2663 \\
$\mathrm{C}_{5}$ & 1.5449 & 1.5448 & 1.5528 & 1.5866 & 1.5448 & 1.5548 \\
\hline
\end{tabular}

Should the matrix have greater dimensions, it will be timeconsuming to calculate eigenvalues and eigenvectors.

Saaty and Vargas [35] formulated LSM as follows [37]:

$$
\begin{gathered}
\min \quad z=\sum_{i=1}^{n} \sum_{j=1}^{n}\left(\frac{a_{i j}-w_{i}}{w_{j}}\right)^{2} \\
\text { s.t. } \quad \sum_{i=1}^{n} w_{i}=1, \\
w_{i} \geq 0 \\
i=1, \ldots, n .
\end{gathered}
$$

Model (11) is clearly non-linear.

Chu et al. [10] formulated WLSM as follows:

$$
\begin{gathered}
\min \quad z=\sum_{i=1}^{n} \sum_{j=1}^{n}\left(a_{i j} w_{j}-w_{i}\right)^{2} \\
\text { s.t. } \quad \sum_{i=1}^{n} w_{i}=1, \\
w_{i} \geq 0 \\
i=1, \ldots, n .
\end{gathered}
$$

Model (12) is also non-linear.

Crawford [11] formulated LLSM as follows:

$$
\begin{gathered}
\min \quad z=\sum_{i=1}^{n} \sum_{j=1}^{n}\left(\ln a_{i j}-\ln \left(w_{i} / w_{j}\right)\right)^{2} \\
\text { s.t. } \quad \sum_{i=1}^{n} w_{i}=1 \\
w_{i} \geq 0 \\
i=1, \ldots, n .
\end{gathered}
$$

By solving Model (13), which is non-linear too, $w_{i}$ $(i=1, \ldots, n)$ will be computed.

By an overview, it can be stated that Ordinary Least Squares (OLS) and LLSM minimize arithmetic mean of errors and geometric mean of errors respectively.

Wang et al. [36] formulated CCMA as follows:

$$
\begin{aligned}
& \operatorname{Max} J=\sum_{i=1}^{n} \sum_{j=1}^{n}\left(a_{i j}-\frac{1 / n+\beta \widehat{w}_{i}^{*}}{1 / n+\beta \widehat{w}_{j}^{*}}\right)^{2}, \\
& \text { s.t. } \quad \beta \geq 0,
\end{aligned}
$$

where $\widehat{w}_{i}^{*}$ is calculated by the following equations:

$$
\begin{aligned}
& \widehat{w}_{i}^{*}=\frac{\sum_{j=1}^{n} b_{i j}}{\sqrt{\sum_{i=1}^{n}\left(\sum_{j=1}^{n} b_{i j}\right)^{2}}}, \quad i=1, \ldots, n, \\
& b_{i j}=\frac{a_{i j}-\bar{a}_{j}}{\sqrt{\sum_{k=1}^{n}\left(a_{k j}-\bar{a}_{j}\right)^{2}}}, \quad i, j=1, \ldots, n,
\end{aligned}
$$

where $\bar{a}_{j}=1 / n \sum_{i=1}^{n} a_{i j}$. 


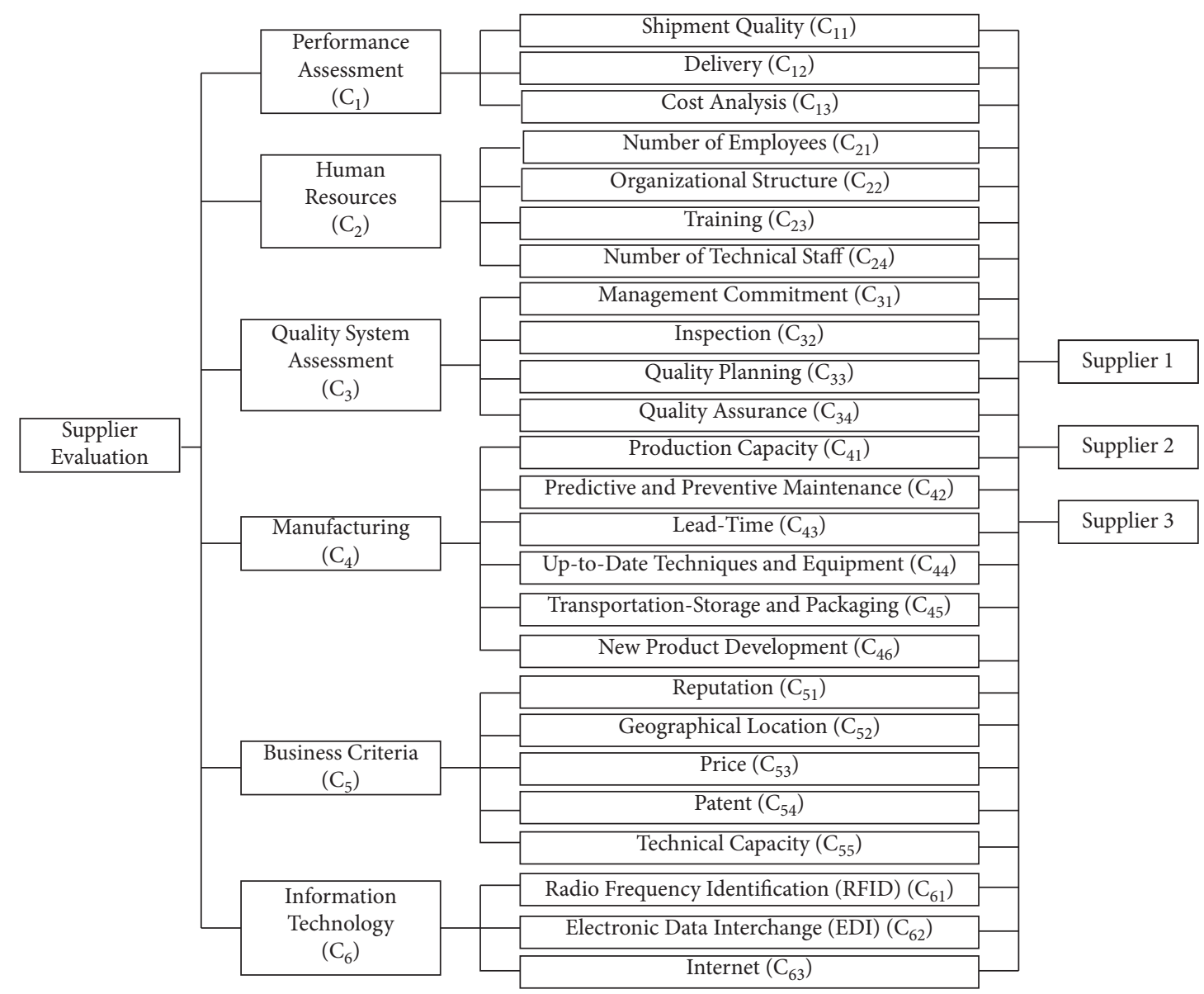

Figure 1: Hierarchical structure of supplier selection problem.

Table 4: Pairwise comparison matrix for six criteria and their local weight.

\begin{tabular}{lcccccccc}
\hline Criteria & $\mathrm{C}_{1}$ & $\mathrm{C}_{2}$ & $\mathrm{C}_{3}$ & $\mathrm{C}_{4}$ & $\mathrm{C}_{5}$ & $\mathrm{C}_{6}$ & EM weights & Model (8) \\
\hline $\mathrm{C}_{1}$ & 1 & 4 & 3 & 2 & $1 / 2$ & 7 & 0.245 & 7.586 \\
$\mathrm{C}_{2}$ & $1 / 4$ & 1 & $1 / 2$ & $1 / 3$ & $1 / 8$ & 2 & 0.054 & 1.690 \\
$\mathrm{C}_{3}$ & $1 / 3$ & 2 & 1 & $1 / 2$ & $1 / 5$ & 4 & 0.094 \\
$\mathrm{C}_{4}$ & $1 / 2$ & 3 & 2 & 1 & $1 / 3$ & 5 & 0.153 & 0.922 \\
$\mathrm{C}_{5}$ & 2 & 8 & 5 & 3 & 1 & 9 & 0.732 \\
$\mathrm{C}_{6}$ & $1 / 7$ & $1 / 2$ & 4 & $1 / 5$ & $1 / 9$ & 1 & 13.108 \\
\hline
\end{tabular}

Consistency ratio 0.0128 .

TABle 5: Pairwise comparison matrix for three subcriteria of $\mathrm{C}_{1}$ and their local weights.

\begin{tabular}{lccccc}
\hline Criteria & $\mathrm{C}_{11}$ & $\mathrm{C}_{12}$ & $\mathrm{C}_{13}$ & EM weights & Model (8) \\
\hline $\mathrm{C}_{11}$ & 1 & 5 & 6 & 0.726 & 0.172 \\
$\mathrm{C}_{12}$ & $1 / 5$ & 1 & 2 & 0.102 & 1.684 \\
$\mathrm{C}_{13}$ & $1 / 6$ & $1 / 2$ & 1 & 1.000 \\
\hline
\end{tabular}

Consistency ratio 0.0251 .

TABle 6: Pairwise comparison matrix for four subcriteria of $\mathrm{C}_{2}$ and their local weights.

\begin{tabular}{lcccccc}
\hline Criteria & $\mathrm{C}_{21}$ & $\mathrm{C}_{22}$ & $\mathrm{C}_{23}$ & $\mathrm{C}_{24}$ & EM weights & Model (8) \\
\hline $\mathrm{C}_{21}$ & 1 & $1 / 5$ & $1 / 6$ & $1 / 3$ & 0.061 & 0.310 \\
$\mathrm{C}_{22}$ & 5 & 1 & $1 / 2$ & 3 & 0.495 & 5.011 \\
$\mathrm{C}_{23}$ & 6 & 2 & 1 & 4 & 0.134 & 8.022 \\
$\mathrm{C}_{24}$ & 3 & $1 / 3$ & $1 / 4$ & 1 & 2.165 \\
\hline
\end{tabular}

Consistency ratio 0.0292 . 
Table 7: Pairwise comparison matrix for four subcriteria of $C_{3}$ and their local weights.

\begin{tabular}{lcccccc}
\hline Criteria & $\mathrm{C}_{31}$ & $\mathrm{C}_{32}$ & $\mathrm{C}_{33}$ & $\mathrm{C}_{34}$ & EM weights & Model (8) \\
\hline $\mathrm{C}_{31}$ & 1 & $1 / 4$ & $1 / 4$ & $1 / 6$ & 0.060 & 0.156 \\
$\mathrm{C}_{32}$ & 4 & 1 & $1 / 3$ & $1 / 3$ & 0.273 & 2.564 \\
$\mathrm{C}_{33}$ & 4 & 3 & 1 & $1 / 3$ & 1 & 0.512 \\
$\mathrm{C}_{34}$ & 6 & 3 & 3 & & 8.383 \\
\hline
\end{tabular}

Consistency ratio 0.0717 .

TABle 8: Pairwise comparison matrix for six subcriteria of $\mathrm{C}_{4}$ and their local weights.

\begin{tabular}{lcccccccc}
\hline Criteria & $\mathrm{C}_{41}$ & $\mathrm{C}_{42}$ & $\mathrm{C}_{43}$ & $\mathrm{C}_{44}$ & $\mathrm{C}_{45}$ & $\mathrm{C}_{46}$ & EM weights & Model (8) \\
\hline $\mathrm{C}_{41}$ & 1 & 2 & 3 & $1 / 2$ & 4 & $1 / 3$ & 0.152 & 0.061 \\
$\mathrm{C}_{42}$ & $1 / 2$ & 1 & $1 / 2$ & $1 / 4$ & 2 & $1 / 7$ & 1.956 \\
$\mathrm{C}_{43}$ & $1 / 3$ & 2 & 1 & $1 / 3$ & 2 & $1 / 6$ & 0.079 & 0.241 \\
$\mathrm{C}_{44}$ & 2 & 4 & 3 & 1 & 6 & $1 / 2$ & 0.038 & 6.266 \\
$\mathrm{C}_{45}$ & $1 / 4$ & $1 / 2$ & $1 / 2$ & $1 / 6$ & 1 & $1 / 9$ & 1.000 \\
$\mathrm{C}_{46}$ & 3 & 7 & 6 & 2 & 9 & 1 & 0.428 & 11.143 \\
\hline
\end{tabular}

Consistency ratio 0.0168 .

Table 9: Pairwise comparison matrix for five subcriteria of $C_{5}$ and their local weights.

\begin{tabular}{lccccccc}
\hline Criteria & $\mathrm{C}_{51}$ & $\mathrm{C}_{52}$ & $\mathrm{C}_{53}$ & $\mathrm{C}_{54}$ & $\mathrm{C}_{55}$ & EM weights & Model (8) \\
\hline $\mathrm{C}_{51}$ & 1 & 2 & $1 / 8$ & $1 / 3$ & $1 / 7$ & $1 / 052$ & 0.035 \\
$\mathrm{C}_{52}$ & $1 / 2$ & 1 & $1 / 9$ & $1 / 5$ & 2 & 0.479 & 1.000 \\
$\mathrm{C}_{53}$ & 8 & 9 & 1 & 5 & $1 / 3$ & 0.128 & 3.745 \\
$\mathrm{C}_{54}$ & 3 & 5 & $1 / 5$ & 1 & 1 & 0.306 & 8.754 \\
$\mathrm{C}_{55}$ & 7 & 8 & $1 / 2$ & 3 & & \\
\hline
\end{tabular}

Consistency ratio 0.0294 .

TABle 10: Pairwise comparison matrix for three subcriteria of $\mathrm{C}_{6}$ and their local weights.

\begin{tabular}{lccccc}
\hline Criteria & $\mathrm{C}_{61}$ & $\mathrm{C}_{62}$ & $\mathrm{C}_{63}$ & EM weights & Model (8) \\
\hline $\mathrm{C}_{61}$ & 1 & $1 / 6$ & $1 / 7$ & 0.070 & 0.348 \\
$\mathrm{C}_{62}$ & 6 & 1 & $1 / 2$ & 0.582 & 5.005 \\
$\mathrm{C}_{63}$ & 7 & 2 & 1 & 8.361 \\
\hline
\end{tabular}

Consistency ratio 0.0279 .

TABLE 11: Pairwise comparison matrices for three suppliers relative to subcriteria of $\mathrm{C}_{1}$ and their local weights.

\begin{tabular}{lcccc}
\hline Supplier & Supplier1 & Supplier 2 & Supplier 3 & EM weights \\
\hline A. Comparison of suppliers & with respect to shipment & Muality $\left(C_{11}\right)$ & (consistency ratio 0.0332) & \\
Supplier 1 & 1 & 3 & 5 & 0.637 \\
Supplier 2 & $1 / 3$ & 1 & 3 & 0.258 \\
Supplier 3 & $1 / 5$ & $1 / 3$ & 1 & 0.105 \\
\hline B. Comparison of suppliers & with respect to delivery $\left(C_{12}\right)$ (consistency ratio & $0.0251)$ & \\
Supplier 1 & 1 & $1 / 5$ & $1 / 6$ & 0.081 \\
Supplier 2 & 5 & 1 & $1 / 2$ & 0.342 \\
Supplier 3 & 6 & 2 & 1 & 0.577 \\
\hline C. Comparison of suppliers & with respect to cost $\left(C_{13}\right)($ consistency ratio 0$)$ & & \\
Supplier 1 & 1 & $1 / 3$ & $1 / 6$ & 0.100 \\
Supplier 2 & 3 & 1 & $1 / 2$ & 0.300 \\
Supplier 3 & 6 & 2 & 1 & 0.600 \\
\hline
\end{tabular}


TABLE 12: Pairwise comparison matrices for three suppliers relative to subcriteria of $\mathrm{C}_{2}$ and their local weights.

\begin{tabular}{|c|c|c|c|c|c|}
\hline Supplier & Supplier 1 & Supplier 2 & Supplier 3 & EM weights & Model (8) \\
\hline \multicolumn{6}{|c|}{ A. Comparison of suppliers with respect to the number of employees $\left(C_{21}\right)$ (consistency ratio 0.0032) } \\
\hline Supplier 1 & 1 & $1 / 3$ & $1 / 5$ & 0.109 & 1.000 \\
\hline Supplier 2 & 3 & 1 & $1 / 2$ & 0.309 & 2.823 \\
\hline Supplier 3 & 5 & 2 & 1 & 0.582 & 5.313 \\
\hline \multicolumn{6}{|c|}{ B. Comparison of suppliers with respect to organization structure $\left(C_{22}\right)$ (consistency ratio 0.0462$)$} \\
\hline Supplier 1 & 1 & 4 & 6 & 0.691 & 7.526 \\
\hline Supplier 2 & $1 / 4$ & 1 & 3 & 0.218 & 2.373 \\
\hline Supplier 3 & $1 / 6$ & $1 / 3$ & 1 & 0.091 & 1.000 \\
\hline \multicolumn{6}{|c|}{ C. Comparison of suppliers with respect to the number training $\left(C_{23}\right)$ (consistency ratio 0.0462$)$} \\
\hline Supplier 1 & 1 & 4 & 6 & 0.691 & 7.526 \\
\hline Supplier 2 & $1 / 4$ & 1 & 3 & 0.218 & 2.373 \\
\hline Supplier 3 & $1 / 6$ & $1 / 3$ & 1 & 0.091 & 1.000 \\
\hline \multicolumn{6}{|c|}{ D. Comparison of suppliers with respect to the number of technical staff $\left(C_{24}\right)$ (consistency ratio 0.0032) } \\
\hline Supplier 1 & 1 & $1 / 3$ & 2 & 0.230 & 1.882 \\
\hline Supplier 2 & 3 & 1 & 5 & 0.648 & 5.313 \\
\hline Supplier 3 & $1 / 2$ & $1 / 5$ & 1 & 0.122 & 1.000 \\
\hline
\end{tabular}

TABLE 13: Pairwise comparison matrices for three suppliers relative to subcriteria of $C_{3}$ and their local weights.

\begin{tabular}{|c|c|c|c|c|c|}
\hline Supplier & Supplier 1 & Supplier 2 & Supplier 3 & EM weights & Model (8) \\
\hline \multicolumn{6}{|c|}{ A. Comparison of suppliers with respect to management commitment $\left(C_{31}\right)$ (consistency ratio 0.0739) } \\
\hline Supplier 1 & 1 & 4 & 5 & 0.674 & 6.635 \\
\hline Supplier 2 & $1 / 4$ & 1 & 3 & 0.226 & 2.226 \\
\hline Supplier 3 & $1 / 5$ & $1 / 3$ & 1 & 0.100 & 1.000 \\
\hline \multicolumn{6}{|c|}{ B. Comparison of suppliers with respect to inspection and control $\left(C_{32}\right)$ (consistency ratio 0.0559) } \\
\hline Supplier 1 & 1 & 5 & 7 & 0.731 & 8.972 \\
\hline Supplier 2 & $1 / 5$ & 1 & 3 & 0.188 & 2.316 \\
\hline Supplier 3 & $1 / 7$ & $1 / 3$ & 1 & 0.081 & 1.000 \\
\hline \multicolumn{6}{|c|}{ C. Comparison of suppliers with respect to quality planning $\left(C_{33}\right)$ (consistency ratio 0.0187 ) } \\
\hline Supplier 1 & 1 & 7 & 9 & 0.793 & 10.416 \\
\hline Supplier 2 & $1 / 7$ & 1 & 2 & 0.131 & 1.724 \\
\hline Supplier 3 & $1 / 9$ & $1 / 2$ & 1 & 0.076 & 1.000 \\
\hline \multicolumn{6}{|c|}{ D. Comparison of suppliers with respect to quality assurance $\left(C_{34}\right)$ (consistency ratio 0.0559 ) } \\
\hline Supplier 1 & 1 & 5 & 7 & 0.731 & 8.972 \\
\hline Supplier 2 & $1 / 5$ & 1 & 3 & 0.188 & 2.316 \\
\hline Supplier 3 & $1 / 7$ & $1 / 3$ & 1 & 0.081 & 1.000 \\
\hline
\end{tabular}

TABLE 14: Pairwise comparison matrices for three suppliers relative to subcriteria of $\mathrm{C}_{4}$ and their local weights.

\begin{tabular}{|c|c|c|c|c|c|}
\hline Supplier & Supplier 1 & Supplier 2 & Supplier 3 & EM weights & Model (8) \\
\hline \multicolumn{6}{|c|}{ A. Comparison of suppliers with respect to production capacity $\left(C_{41}\right)$ (consistency ratio 0.0739$)$} \\
\hline Supplier 1 & 1 & $1 / 5$ & $1 / 4$ & 0.094 & 1.000 \\
\hline Supplier 2 & 5 & 1 & 3 & 0.627 & 6.635 \\
\hline Supplier 3 & 4 & $1 / 3$ & 1 & 0.280 & 2.968 \\
\hline \multicolumn{6}{|c|}{ B. Comparison of suppliers with respect to predictive and preventive maintenance $\left(C_{42}\right)$ (consistency ratio 0.0332) } \\
\hline Supplier 1 & 1 & $3^{1}$ & 5 & 0.637 & 6.066 \\
\hline Supplier 2 & $1 / 3$ & 1 & 3 & 0.258 & 2.461 \\
\hline Supplier 3 & $1 / 5$ & $1 / 3$ & 1 & 0.105 & 1.000 \\
\hline \multicolumn{6}{|c|}{ C. Comparison of suppliers with respect to lead-time $\left(C_{43}\right)$ (consistency ratio 0.0212 ) } \\
\hline Supplier 1 & 1 & 2 & $1 / 4$ & 0.200 & 1.708 \\
\hline Supplier 2 & $1 / 2$ & 1 & $1 / 5$ & 0.117 & 1.000 \\
\hline Supplier 3 & 4 & 5 & 1 & 0.683 & 5.840 \\
\hline \multicolumn{6}{|c|}{ D. Comparison of suppliers with respect to up-to-date techniques and equipment $\left(C_{44}\right)$ (consistency ratio 0$)$} \\
\hline Supplier 1 & 1 & 1 & 4 & 0.444 & 4.000 \\
\hline Supplier 2 & 1 & 1 & 4 & 0.444 & 4.000 \\
\hline
\end{tabular}


Table 14: Continued.

\begin{tabular}{|c|c|c|c|c|c|}
\hline Supplier & Supplier 1 & Supplier 2 & Supplier 3 & EM weights & Model (8) \\
\hline Supplier 3 & $1 / 4$ & $1 / 4$ & 1 & 0.111 & 1.000 \\
\hline \multicolumn{6}{|c|}{ E. Comparison of suppliers with respect to transportation-storage and packaging $\left(C_{45}\right)$ (consistency ratio 0.0634$)$} \\
\hline Supplier 1 & 1 & 3 & $1 / 3$ & 0.268 & 2.277 \\
\hline Supplier 2 & $1 / 3$ & 1 & $1 / 4$ & 0.117 & 1.000 \\
\hline Supplier 3 & 3 & 4 & 1 & 0.614 & 5.205 \\
\hline \multicolumn{6}{|c|}{ F. Comparison of suppliers with respect to new product development $\left(C_{46}\right)$ (consistency ratio 0.0634 ) } \\
\hline Supplier 1 & 1 & $1 / 3$ & 6 & 0.285 & 4.554 \\
\hline Supplier 2 & 3 & 1 & 8 & 0.653 & 10.409 \\
\hline Supplier 3 & $1 / 6$ & $1 / 8$ & 1 & 0.062 & 1.000 \\
\hline
\end{tabular}

TABLE 15: Pairwise comparison matrices for three suppliers relative to subcriteria of $\mathrm{C}_{5}$ and their local weights.

\begin{tabular}{|c|c|c|c|c|c|}
\hline Supplier & Supplier 1 & Supplier 2 & Supplier 3 & EM weights & Model (8) \\
\hline \multicolumn{6}{|c|}{ A. Comparison of suppliers with respect to reputation $\left(C_{51}\right)$ (consistency ratio 0.0634$)$} \\
\hline Supplier 1 & 1 & 3 & 8 & 0.653 & 10.409 \\
\hline Supplier 2 & $1 / 3$ & 1 & 6 & 0.285 & 4.554 \\
\hline Supplier 3 & $1 / 8$ & $1 / 6$ & 1 & 0.062 & 1.000 \\
\hline \multicolumn{6}{|c|}{ B. Comparison of suppliers with respect to geographical location $\left(C_{52}\right)$ (consistency ratio 0.0739) } \\
\hline Supplier 1 & 1 & 4 & 5 & 0.674 & 6.635 \\
\hline Supplier 2 & $1 / 4$ & 1 & 3 & 0.226 & 2.226 \\
\hline Supplier 3 & $1 / 5$ & $1 / 3$ & 1 & 0.101 & 1.000 \\
\hline \multicolumn{6}{|c|}{ C. Comparison of suppliers with respect to price $\left(C_{53}\right)$ (consistency ratio 0.0634) } \\
\hline Supplier 1 & 1 & $1 / 3$ & $1 / 4$ & 0.117 & 1.000 \\
\hline Supplier 2 & 3 & 1 & $1 / 3$ & 0.268 & 2.277 \\
\hline Supplier 3 & 4 & 3 & 1 & 0.614 & 5.205 \\
\hline \multicolumn{6}{|c|}{ D. Comparison of suppliers with respect to patents $\left(C_{54}\right)$ (consistency ratio 0) } \\
\hline Supplier 1 & 1 & 1 & 1 & 0.333 & 1.000 \\
\hline Supplier 2 & 1 & 1 & 1 & 0.333 & 1.000 \\
\hline Supplier 3 & 1 & 1 & 1 & 0.333 & 1.000 \\
\hline \multicolumn{6}{|c|}{ E. Comparison of suppliers with respect to technical capability $\left(C_{55}\right)$ (consistency ratio 0.0614$)$} \\
\hline Supplier 1 & 1 & $1 / 4$ & 5 & 0.231 & 3.312 \\
\hline Supplier 2 & 4 & 1 & 9 & 0.709 & 11.666 \\
\hline Supplier 3 & $1 / 5$ & $1 / 9$ & 1 & 0.060 & 1.000 \\
\hline
\end{tabular}

TABle 16: Pairwise comparison matrices for three suppliers relative to subcriteria of $\mathrm{C}_{6}$ and their local weights.

\begin{tabular}{lcccc}
\hline Supplier & Supplier 1 & Supplier 2 & Supplier 3 & EM weights \\
\hline A. Comparison of suppliers & with respect to RFID $\left(C_{61}\right)$ (consistency ratio 0$)$ & & \\
Supplier 1 & 1 & 1 & 3 & 0.429 \\
Supplier 2 & 1 & 1 & 3 & 0.429 \\
Supplier 3 & $1 / 3$ & $1 / 3$ & 1 & 0.143 \\
\hline B. Comparison of suppliers & with respect to EDI $\left(C_{62}\right)$ (consistency ratio 0$)$ & & \\
Supplier 1 & 1 & 1 & 3 & 0.429 \\
Supplier 2 & 1 & 1 & 3 & 0.429 \\
Supplier 3 & $1 / 3$ & $1 / 3$ & 1 & 0.143 \\
C. Comparison of suppliers & with respect to internet $\left(C_{63}\right)$ (consistency ratio 0$)$ & & \\
Supplier 1 & 1 & 1 & 3 & 0.429 \\
Supplier 2 & 1 & 1 & 3 & 0.429 \\
Supplier 3 & $1 / 3$ & $1 / 3$ & 1 & 0.143 \\
\hline
\end{tabular}


TABle 17: Compound weights of three suppliers from the view of $\mathrm{C}_{1}$.

\begin{tabular}{|c|c|c|c|c|c|}
\hline & $\mathrm{C}_{11}$ & $\mathrm{C}_{12}$ & $\mathrm{C}_{13}$ & Compound weight & Normalisation \\
\hline \multicolumn{6}{|c|}{ A. EM weights are normalised to make their maximum one } \\
\hline Subcriteria weight & 1.000 & 0.237 & 0.141 & & \\
\hline Supplier 1 & 1.000 & 0.141 & 0.167 & 1.057 & 1.000 \\
\hline Supplier 2 & 0.405 & 0.593 & 0.500 & 0.616 & 0.583 \\
\hline Supplier 3 & 0.164 & 1.000 & 1.000 & 0.542 & 0.513 \\
\hline \multicolumn{6}{|c|}{ B. Model (8) weights are normalised to make their maximum one } \\
\hline Subcriteria weight & 1.000 & 0.237 & 0.141 & & \\
\hline Supplier 1 & 1.000 & 0.141 & 0.167 & 1.057 & 1.000 \\
\hline Supplier 2 & 0.406 & 0.593 & 0.500 & 0.617 & 0.584 \\
\hline Supplier 3 & 0.165 & 1.000 & 1.000 & 0.543 & 0.514 \\
\hline
\end{tabular}

TABle 18: Compound weights of three suppliers from the view of $\mathrm{C}_{2}$.

\begin{tabular}{|c|c|c|c|c|c|c|}
\hline & $\mathrm{C}_{21}$ & $\mathrm{C}_{22}$ & $\mathrm{C}_{23}$ & $\mathrm{C}_{24}$ & Compound weight & Normalisation \\
\hline \multicolumn{7}{|c|}{ A. EM weights are normalised to make their maximum one } \\
\hline Subcriteria weight & 0.124 & 0.627 & 1.000 & 0.270 & & \\
\hline Supplier 1 & 0.188 & 1.000 & 1.000 & 0.354 & 1.746 & 1.000 \\
\hline Supplier 2 & 0.531 & 0.315 & 0.323 & 1.000 & 0.856 & 0.490 \\
\hline Supplier 3 & 1.000 & 0.132 & 0.136 & 0.188 & 0.394 & 0.225 \\
\hline \multicolumn{7}{|c|}{ B. Model (8) weights are normalised to make their maximum one } \\
\hline Subcriteria weight & 0.125 & 0.625 & 1.000 & 0.270 & & \\
\hline Supplier 1 & 0.188 & 1.000 & 1.000 & 0.354 & 1.746 & 1.000 \\
\hline Supplier 2 & 0.531 & 0.315 & 0.315 & 1.000 & 0.856 & 0.490 \\
\hline Supplier 3 & 1.000 & 0.133 & 0.133 & 0.188 & 0.394 & 0.225 \\
\hline
\end{tabular}

TABLE 19: Compound weights of three suppliers from the view of $\mathrm{C}_{3}$.

\begin{tabular}{|c|c|c|c|c|c|c|}
\hline & $\mathrm{C}_{31}$ & $\mathrm{C}_{32}$ & $\mathrm{C}_{33}$ & $\mathrm{C}_{34}$ & Compound weight & Normalisation \\
\hline \multicolumn{7}{|c|}{ A. EM weights are normalised to make their maximum one } \\
\hline Subcriteria weight & 0.117 & 0.304 & 0.533 & 1.000 & & \\
\hline Supplier 1 & 1.000 & 1.000 & 1.000 & 1.000 & 1.955 & 1.000 \\
\hline Supplier 2 & 0.335 & 0.258 & 0.166 & 0.258 & 0.464 & 0.237 \\
\hline Supplier 3 & 0.149 & 0.111 & 0.096 & 0.111 & 0.213 & 0.109 \\
\hline \multicolumn{7}{|c|}{ B. Model (8) weights are normalised to make their maximum one } \\
\hline Subcriteria weight & 0.118 & 0.303 & 0.518 & 1.000 & & \\
\hline Supplier 1 & 1.000 & 1.000 & 1.000 & 1.000 & 1.939 & 1.000 \\
\hline Supplier 2 & 0.335 & 0.258 & 0.166 & 0.258 & 0.462 & 0.238 \\
\hline Supplier 3 & 0.151 & 0.111 & 0.096 & 0.111 & 0.212 & 0.109 \\
\hline
\end{tabular}

TABle 20: Compound weights of three suppliers from the view of $\mathrm{C}_{4}$.

\begin{tabular}{|c|c|c|c|c|c|c|c|c|}
\hline & $\mathrm{C}_{41}$ & $\mathrm{C}_{42}$ & $\mathrm{C}_{43}$ & $\mathrm{C}_{44}$ & $\mathrm{C}_{45}$ & $\mathrm{C}_{46}$ & Compound weight & Normalisation \\
\hline \multicolumn{9}{|c|}{ A. EM weights are normalised to make their maximum one } \\
\hline Subcriteria weight & 0.355 & 0.143 & 0.184 & 0.563 & 0.090 & 1.000 & & \\
\hline Supplier 1 & 0.149 & 1.000 & 0.292 & 1.000 & 0.437 & 0.437 & 1.289 & 0.637 \\
\hline Supplier 2 & 1.000 & 0.405 & 0.171 & 1.000 & 0.191 & 1.000 & 2.025 & 1.000 \\
\hline Supplier 3 & 0.446 & 0.164 & 1.000 & 0.250 & 1.000 & 0.095 & 0.692 & 0.342 \\
\hline \multicolumn{9}{|c|}{ B. Model (8) weights are normalised to make their maximum one } \\
\hline Subcriteria weight & 0.355 & 0.143 & 0.183 & 0.562 & 0.090 & 1.000 & & \\
\hline Supplier 1 & 0.151 & 1.000 & 0.292 & 1.000 & 0.437 & 0.438 & 1.289 & 0.637 \\
\hline Supplier 2 & 1.000 & 0.406 & 0.171 & 1.000 & 0.192 & 1.000 & 2.023 & 1.000 \\
\hline Supplier 3 & 0.447 & 0.165 & 1.000 & 0.250 & 1.000 & 0.096 & 0.692 & 0.342 \\
\hline
\end{tabular}


TABLE 21: Compound weights of three suppliers from the view of $\mathrm{C}_{5}$.

\begin{tabular}{|c|c|c|c|c|c|c|c|}
\hline & $\mathrm{C}_{51}$ & $\mathrm{C}_{52}$ & $\mathrm{C}_{53}$ & $\mathrm{C}_{54}$ & $\mathrm{C}_{55}$ & Compound weight & Normalisation \\
\hline \multicolumn{8}{|c|}{ A. EM weights are normalised to make their maximum one } \\
\hline Subcriteria weight & 0.109 & 0.072 & 1.000 & 0.266 & 0.639 & & \\
\hline Supplier 1 & 1.000 & 1.000 & 0.191 & 1.000 & 0.326 & 0.847 & 0.599 \\
\hline Supplier 2 & 0.437 & 0.335 & 0.437 & 1.000 & 1.000 & 1.414 & 1.000 \\
\hline Supplier 3 & 0.095 & 0.149 & 1.000 & 1.000 & 0.085 & 1.342 & 0.949 \\
\hline \multicolumn{8}{|c|}{ B. Model (8) weights are normalised to make their maximum one } \\
\hline Subcriteria weight & 0.109 & 0.073 & 1.000 & 0.266 & 0.637 & & \\
\hline Supplier 1 & 1.000 & 1.000 & 0.192 & 1.000 & 0.284 & 0.821 & 0.581 \\
\hline Supplier 2 & 0.438 & 0.335 & 0.437 & 1.000 & 1.000 & 1.412 & 1.000 \\
\hline Supplier 3 & 0.096 & 0.151 & 1.000 & 1.000 & 0.086 & 1.342 & 0.950 \\
\hline
\end{tabular}

TABLE 22: Compound weights of three suppliers from the view of $\mathrm{C}_{6}$.

\begin{tabular}{|c|c|c|c|c|c|}
\hline & $\mathrm{C}_{61}$ & $\mathrm{C}_{62}$ & $\mathrm{C}_{63}$ & Compound weight & Normalisation \\
\hline \multicolumn{6}{|c|}{ A. EM weights are normalised to make their maximum one } \\
\hline Subcriteria weight & 0.119 & 0.598 & 1.000 & & \\
\hline Supplier 1 & 1.000 & 1.000 & 1.000 & 1.718 & 1.000 \\
\hline Supplier 2 & 1.000 & 1.000 & 1.000 & 1.718 & 1.000 \\
\hline Supplier 3 & 0.333 & 0.333 & 0.333 & 0.573 & 0.333 \\
\hline \multicolumn{6}{|c|}{ B. Model (8) weights are normalised to make their maximum one } \\
\hline Subcriteria weight & 0.119 & 0.598 & 1.000 & & \\
\hline Supplier 1 & 1.000 & 1.000 & 1.000 & 1.718 & 1.000 \\
\hline Supplier 2 & 1.000 & 1.000 & 1.000 & 1.718 & 1.000 \\
\hline Supplier 3 & 0.333 & 0.333 & 0.333 & 0.573 & 0.333 \\
\hline
\end{tabular}

TABLE 23: Global weights of the three suppliers with respect to the total Goa.

\begin{tabular}{|c|c|c|c|c|c|c|c|c|}
\hline & $\mathrm{C}_{1}$ & $\mathrm{C}_{2}$ & $\mathrm{C}_{3}$ & $\mathrm{C}_{4}$ & $\mathrm{C}_{5}$ & $\mathrm{C}_{6}$ & Global weight & Normalisation \\
\hline \multicolumn{9}{|c|}{ A. EM weights are normalised to make their maximum one } \\
\hline Criteria weight & 0.580 & 0.129 & 0.224 & 0.362 & 1.000 & 0.076 & & \\
\hline Supplier 1 & 1.000 & 1.000 & 1.000 & 0.637 & 0.599 & 1.000 & 1.838 & 0.971 \\
\hline Supplier 2 & 0.583 & 0.490 & 0.237 & 1.000 & 1.000 & 1.000 & 1.892 & 1.000 \\
\hline Supplier 3 & 0.513 & 0.225 & 0.109 & 0.342 & 0.949 & 0.333 & 1.449 & 0.766 \\
\hline \multicolumn{9}{|c|}{ B. Model (8) weights are normalised to make their maximum one } \\
\hline Criteria weight & 0.579 & 0.129 & 0.223 & 0.361 & 1.000 & 0.076 & & \\
\hline Supplier 1 & 1.000 & 1.000 & 1.000 & 0.637 & 0.581 & 1.000 & 1.818 & 0.961 \\
\hline Supplier 2 & 0.584 & 0.490 & 0.238 & 1.000 & 1.000 & 1.000 & 1.891 & 1.000 \\
\hline Supplier 3 & 0.514 & 0.225 & 0.109 & 0.342 & 0.950 & 0.333 & 1.450 & 0.767 \\
\hline
\end{tabular}

TABLE 24: Priority vectors and ranking order obtained from different prioritization methods.

\begin{tabular}{|c|c|c|c|c|c|c|}
\hline & DEA/AR Model (8) & EM & WLSM & LSM & LLSM & CCMA \\
\hline$w_{1}$ & $9.0062(3)$ & $0.1730(3)$ & $0.1427(2)$ & $0.2202(2)$ & $0.1748(2)$ & $0.1815(3)$ \\
\hline$w_{2}$ & $2.8338(5)$ & $0.0540(5)$ & $0.0543(5)$ & $0.0468(5)$ & $0.0626(5)$ & $0.0825(5)$ \\
\hline$w_{3}$ & $10.4515(2)$ & $0.1881(2)$ & $0.1213(3)$ & $0.1494(4)$ & $0.1487(4)$ & $0.1508(4)$ \\
\hline$w_{4}$ & $1.0000(8)$ & $0.0175(8)$ & $0.0301(8)$ & $0.0290(8)$ & $0.0193(8)$ & $0.0214(8)$ \\
\hline$w_{5}$ & $1.7471(7)$ & $0.0310(7)$ & $0.0465(6)$ & $0.0413(7)$ & $0.0356(7)$ & $0.0426(7)$ \\
\hline$w_{6}$ & $2.0066(6)$ & $0.0363(6)$ & $0.0465(6)$ & $0.0416(6)$ & $0.0423(6)$ & $0.0565(6)$ \\
\hline$w_{7}$ & $8.8996(4)$ & $0.1668(4)$ & $0.0891(4)$ & $0.2029(3)$ & $0.1670(3)$ & $0.1818(2)$ \\
\hline$w_{8}$ & $18.1511(1)$ & $0.3332(1)$ & $0.4695(1)$ & $0.2687(1)$ & $0.3496(1)$ & $0.2829(1)$ \\
\hline
\end{tabular}


Example 3. Consider the following inconsistent comparison matrix studied by Lipovetsky and Conklin [38]:

$$
A=\left[\begin{array}{cccccccc}
1 & 5 & 3 & 7 & 6 & 6 & 1 / 3 & 1 / 4 \\
1 / 5 & 1 & 1 / 3 & 5 & 3 & 3 & 1 / 5 & 1 / 7 \\
1 / 3 & 3 & 1 & 6 & 3 & 4 & 6 & 1 / 5 \\
1 / 7 & 1 / 5 & 1 / 6 & 1 & 1 / 3 & 1 / 4 & 1 / 7 & 1 / 8 \\
1 / 6 & 1 / 3 & 1 / 3 & 3 & 1 & 1 / 2 & 1 / 5 & 1 / 6 \\
1 / 6 & 1 / 3 & 1 / 4 & 4 & 2 & 1 & 1 / 5 & 1 / 6 \\
3 & 5 & 1 / 6 & 7 & 5 & 5 & 1 & 1 / 2 \\
4 & 7 & 5 & 8 & 6 & 6 & 2 & 1
\end{array}\right] .
$$

In this pairwise comparison matrix, we have $\beta=13.2372$

Table 24 shows priority vectors obtained from different prioritization methods. As can be seen, various prioritization methods generate different rankings. This is mainly due to the fact that the initialization vector $A$ was highly inconsistent and should be therefore adjusted. Lipovetsky and Conklin [37] showed that the order of the adjusted ranking is as $w_{8}>w_{7}>w_{1}>w_{3}>w_{2}>w_{6}>w_{5}>w_{4}$. Ranking in DEA/ AR Model (8) is exactly of the same order as ranking in EM.

\section{Conclusion}

Although obtaining weights in the AHP has already been investigated by different studies, this problem needs more clarification. This paper proposed a new approach for generating weights from a pairwise comparison matrix. The proposed approach considers the most undesirable weight for each decision criterion or alternative and selects a decision criterion or alternative with the greatest weight. Two numerical examples, including BEKO in Turkey on CRT supplier selection, conducted by Sevkli, Lenny Koh [34], were investigated using the proposed approach. Moreover, the proposed method proved its ability to effectively differentiate decision criteria and alternative of DEAHP efficient.

\section{Data Availability}

All of our data are clear, and we have explained their source.

\section{Conflicts of Interest}

The authors declare that they have no conflicts of interest.

\section{References}

[1] P. H. Dos Santos, S. M. Neves, D. O. Sant'Anna, C. H. d. Oliveira, and H. D. Carvalho, "The analytic hierarchy process supporting decision making for sustainable development: an overview of applications," Journal of Cleaner Production, vol. 212, pp. 119-138, 2019.

[2] Y.-M. Wang and K.-S. Chin, "A linear programming approximation to the eigenvector method in the analytic hierarchy process," Information Sciences, vol. 181, no. 23, pp. 5240-5248, 2011.
[3] S. S. Hosseinian, H. Navidi, and A. Hajfathaliha, "A new linear programming method for weights generation and group decision making in the analytic hierarchy process," Group Decision and Negotiation, vol. 21, no. 3, pp. 233-254, 2012.

[4] J. Zhang, G. Kou, Y. Peng, and Y. Zhang, "Estimating priorities from relative deviations in pairwise comparison matrices," Information Sciences, vol. 552, pp. 310-327, 2021.

[5] S. M. Mirhedayatian and R. Farzipoor Saen, "A new approach for weight derivation using data envelopment analysis in the analytic hierarchy process," Journal of the Operational Research Society, vol. 62, no. 8, pp. 1585-1595, 2011.

[6] Y. M. Wang and Y. Luo, "A note on "A new approach for weight derivation using data envelopment analysis in the analytic hierarchy process"," Mathematical and Computer Modelling, vol. 56, no. 3, pp. 49-55, 2012.

[7] S. Kheybari, F. M. Rezaie, and H. Farazmand, "Analytic network process: an overview of applications," Applied Mathematics and Computation, vol. 367, Article ID 124780, 2020.

[8] A. Emrouznejad and M. Marra, "The state of the art development of AHP (1979-2017): a literature review with a social network analysis," International Journal of Production Research, vol. 55, no. 22, pp. 6653-6675, 2017.

[9] K. O. Cogger and P. L. Yu, "Eigenweight vectors and leastdistance approximation for revealed preference in pairwise weight ratios," Journal of Optimization Theory and Applications, vol. 46, no. 4, pp. 483-491, 1985.

[10] A. T. W. Chu, R. E. Kalaba, and K. Spingarn, "A comparison of two methods for determining the weights of belonging to fuzzy sets," Journal of Optimization Theory and Applications, vol. 27, no. 4, pp. 531-538, 1979.

[11] G. B. Crawford, "The geometric mean procedure for estimating the scale of a judgement matrix," Mathematical Modelling, vol. 9, no. 3, pp. 327-334, 1987.

[12] S. I. Gass and T. Rapcsák, "Singular value decomposition in AHP," European Journal of Operational Research, vol. 154, no. 3, pp. 573-584, 2004.

[13] P. Laininen and R. P. Hämäläinen, "Analyzing AHP-matrices by regression," European Journal of Operational Research, vol. 148, no. 3, pp. 514-524, 2003.

[14] G. Islei and A. G. Lockett, "Judgemental modelling based on geometric least square," European Journal of Operational Research, vol. 36, no. 1, pp. 27-35, 1988.

[15] B. Keskin and C. D. Köksal, "A hybrid AHP/DEA-AR model for measuring and comparing the efficiency of airports," International Journal of Productivity and Performance Management, vol. 68, no. 3, pp. 524-541, 2019.

[16] P. Bajec and D. Tuljak-Suban, "An integrated analytic hierarchy process-slack based measure-data envelopment analysis model for evaluating the efficiency of logistics service providers considering undesirable performance criteria," Sustainability, vol. 11, no. 8, p. 2330, 2019.

[17] Ü. Şengül, M. Eren, and S. E. Shiraz, "Application of linear programming to derive the local weight in the analytic hierarchy process," International Journal of Operational Research, vol. 27, no. 3, p. 450, 2016.

[18] Y.-K. Fu, "An integrated approach to catering supplier selection using AHP-ARAS-MCGP methodology," Journal of Air Transport Management, vol. 75, pp. 164-169, 2019.

[19] T. Saaty, "The analytic hierarchy process," Agricultural Economics Review, vol. 70, 1980.

[20] L. Mikhailov, "A fuzzy programming method for deriving priorities in the analytic hierarchy process," Journal of the Operational Research Society, vol. 51, no. 3, pp. 341-349, 2000. 
[21] B. Srdjevic, "Combining different prioritization methods in the analytic hierarchy process synthesis," Computers \& Operations Research, vol. 32, no. 7, pp. 1897-1919, 2005.

[22] A. Charnes, W. W. Cooper, and E. Rhodes, "Measuring the efficiency of decision making units," European Journal of Operational Research, vol. 2, no. 6, pp. 429-444, 1978.

[23] R. Ramanathan, "Data envelopment analysis for weight derivation and aggregation in the analytic hierarchy process," Computers \& Operations Research, vol. 33, no. 5, pp. 1289-1307, 2006.

[24] Y.-M. Wang, K.-S. Chin, and J. P.-F. Leung, "A note on the application of the data envelopment analytic hierarchy process for supplier selection," International Journal of Production Research, vol. 47, no. 11, pp. 3121-3138, 2009.

[25] Y.-M. Wang, K.-S. Chin, and G. K. K. Poon, "A data envelopment analysis method with assurance region for weight generation in the analytic hierarchy process," Decision Support Systems, vol. 45, no. 4, pp. 913-921, 2008.

[26] Y.-M. Wang, C. Parkan, and Y. Luo, "A linear programming method for generating the most favorable weights from a pairwise comparison matrix," Computers \& Operations Research, vol. 35, no. 12, pp. 3918-3930, 2008.

[27] Y.-M. Wang and K.-S. Chin, "A new data envelopment analysis method for priority determination and group decision making in the analytic hierarchy process," European Journal of Operational Research, vol. 195, no. 1, pp. 239-250, 2009.

[28] Y.-M. Wang, Y. Luo, and Y.-S. Xu, "Cross-weight evaluation for pairwise comparison matrices," Group Decision and Negotiation, vol. 22, no. 3, pp. 483-497, 2013.

[29] J. Aparicio and J. L. Zofío, "Economic cross-efficiency," Omega, vol. 100, Article ID 102374, 2021.

[30] Y. Lin and Y.-M. Wang, "Prioritization of hesitant multiplicative preference relations based on data envelopment analysis for group decision making," Neural Computing \& Applications, vol. 31, no. 2, pp. 437-447, 2019.

[31] H. Azizi and Y.-M. Wang, "Improved DEA models for measuring interval efficiencies of decision-making units," Measurement, vol. 46, no. 3, pp. 1325-1332, 2013.

[32] H. Azizi, "The interval efficiency based on the optimistic and pessimistic points of view," Applied Mathematical Modelling, vol. 35 , no. 5, pp. 2384-2393, 2011.

[33] R. Jahed, A. Amirteimoori, and H. Azizi, "Performance measurement of decision-making units under uncertainty conditions: an approach based on double frontier analysis," Measurement, vol. 69, pp. 264-279, 2015.

[34] M. Sevkli, S. C. Lenny Koh, S. Zaim, M. Demirbag, and E. Tatoglu, "An application of data envelopment analytic hierarchy process for supplier selection: a case study of BEKO in Turkey," International Journal of Production Research, vol. 45, no. 9, pp. 1973-2003, 2007.

[35] T. L. Saaty and L. G. Vargas, "Comparison of eigenvalue, logarithmic least squares and least squares methods in estimating ratios," Mathematical Modelling, vol. 5, no. 5, pp. 309-324, 1984.

[36] Y.-M. Wang, C. Parkan, and Y. Luo, "Priority estimation in the AHP through maximization of correlation coefficient," Applied Mathematical Modelling, vol. 31, no. 12, pp. 27112718, 2007.

[37] E. U. Choo and W. C. Wedley, "A common framework for deriving preference values from pairwise comparison matrices," Computers \& Operations Research, vol. 31, no. 6, pp. 893-908, 2004.

[38] S. Lipovetsky and W. Michael Conklin, "Robust estimation of priorities in the AHP," European Journal of Operational Research, vol. 137, no. 1, pp. 110-122, 2002. 